\title{
Analisis Keterlambatan Pengembalian Berkas Rekam Medis Rawat Inap Ruang Seruni Ke Bagian Assembling Di Rumah Sakit Dr. M. Yunus Bengkulu Tahun 2017
}

\author{
Djusmalinar, Niska Ramadani, Gita Diantika Natalia \\ Akademi Kesehatan Sapta Bakti Bengkulu
}

\begin{abstract}
ABSTRAK
Dokumen rekam medis harus diisi lengkap oleh tenaga medis dalam waktu $<24$ jam setelah selesai pelayanan. Penelitian ini bertujuan untuk menganalisis faktor keterlambatan pengembalian berkas rekam medis (kelengkapan pengisian BRM dan pelaksanaan SOP) BRM rawat inap ke bagian assembling di RSUD Dr. M. Yunus Bengkulu. Jenis penelitian ini adalah observasional dengan rancangan deskriptif. Populasi penelitian ini adalah seluruh Dokumen Rekam Medis (DRM) pasien rawat inap Ruangan Melati pada bulan Januari-Maret 2017 yang berjumlah 500 DRM. Sampel penelitian ini didapat dengan menggunakan rumus besar sampel sehingga diperoleh 318 DRM, diambil dengan menggunakan systematic random sampling. Data penelitian ini menggunakan data primer yang dikumpulkan menggunakan lembar observasi dan pedoman wawancara. Setelah data terkumpul dianalisis secara univariat (menggunakan tabel dan narasi). Hasil penelitian ini didapatkan bahwa, dari 83 BRM yang diobservasi, 67 (80\%) BRM tidak terisi lengkap yaitu pada lembar pemeriksaan umum yang terdiri dari kesadaran, tekanan darah, nadi, suhu, pernafasan, keadaan umum, keadaan gizi. Dari 83 BRM, 63 (76\%) BRM tidak tepat waktu dikembalikan ke ruang Assembling Unit Rekam Medik yaitu selama 5 hari. Berdasarkan wawancara langsung kepada petugas di ruang rawat inap seruni didapatkan bahwa seluruh petugas sudah mengetahui SOP mengenai pengisian dan pengambalian BRM, tetapi pada pelaksanaannya belum dikerjakan sesuai standar. Diharapkan, penanggung jawab ruang rawat inap (Ka.ruang) terus mengingatkan perawat dan dokter yang bertugas sejak pasien dirawat sampai 1 hari setelah pasien pulang untuk melengkapi semua catatan medic pasien per lembar dokumen, agar pengembalian berkas ke unit rekam medic tepat waktu sesuai SOP yang telah ditetapkan.
\end{abstract}

Kata Kunci : Keterlambatan, Pengembalian berkas, Assembling.

\section{PENDAHULUAN}

Menurut Peraturan Menteri Kesehatan Republik Indonesia Nomor 55 Tahun 2013 tentang rekam medis pasal 1 ayat 2 tentang Rekam medis adalah berkas yang berisikan catatan dan dokumen tentang identitas pasien, pemeriksaan, pengobatan, tindakan dan pelayanan lain yang telah diberikan kepada pasien. dalam organisasi rumah sakit terdapat struktur rekam medis yang berguna untuk kelancaran pelayanan rekam medis baik itu rekam medis unit gawat darurat, rawat jalan, dan rawat inap. Rekam medis juga berguna sebagai bukti tertulis atas tindakan pelayanan terhadap seorang pasien, juga mampu melindungi kepentingan hukum bagi pasien yang bersangkutan, rumah sakit maupun dokter dan tenaga kesehatan lainnya, apabila dikemudian hari terjadi suatu hal yang tidak diinginkan menyangkut rekam medis itu sendiri, oleh karena itu dibutuhkan pengelolaan rekam medis yang baik dalam penyelenggaraan rekam medis.

Proses pengelolaan rekam medis terdiri dari beberapa tahapan antara lain dilakukannya assembling, koding, indeksing dan filling (Depkes RI, 2006). Kegiatan assembling diantaranya merakit dokumen rekam medis, mengecek kelengkapan pengisian dokumen rekam medis dan formulir yang harus ada pada dokumen rekam medis. Apabila dokumen rekam medis telah diterima dari ruang rawat inap dengan menggunakan buku ekspedisi pengembalian dokumen rekam medis, bagian assembling akan mencatat pada buku register, semua dokumen rekam medis yang masuk sesuai tanggal masuk ke bagian 
assembling dan tanggal pasien pulang (Budi, 2011).

Dalam mengelola rekam medis, rumah sakit selalu mengacu kepada pedoman atau petunjuk teknis pengelolaan rekam medis yang dibuat oleh rumah sakit yang bersangkutan. Pengelolaan rekam medis di rumah sakit adalah untuk menunjang tercapainya tertib administrasi dalam rangka upaya mencapai tujuan rumah sakit, yaitu peningkatan mutu pelayanan kesehatan di rumah sakit (Giyana, 2012).

Pengelolaan rekam medis yang dilakukan secara seksama dan lebih professional merupakan salah satu pelayanan yang dapat menunjang pemberian pelayanan medis yang cepat, tepat, dan akurat. Setiap staf rumah sakit perlu memahami pentingnya rekam medis dalam memberikan pelayanan, maka rekam medis dipergunakan sebagai bukti tertulis yang dapat dipertanggung jawabkan oleh dokter dan tenaga kesehatan lainnya (Djojodibroto, 1997). Menurut Gafur (2003), pelayanan yang bermutu bukan hanya pada pelayanan medis saja, tetapi juga pada pelayanan penunjang seperti penanganan rekam medis di rumah sakit yang menjadi salah satu indikator mutu pelayanan rumah sakit yang dapat diketahui melalui kelengkapan pengisian rekam medis. Sedangkan jika mengacu pada pedoman standar pelayanan minimal (SPM) rumah sakit, terdapat empat indikator sasaran mutu yang salah satunya ketepatan waktu penyediaan dokumen rekam medis (Depkes RI, 2008).

Rekam medis harus ditulis segera secara lengkap dan ditanda tangani oleh dokter yang merawat pasien 2x24 jam setelah pasien selesai dalam perawatan. Waktu 2 hari adalah waktu maksimum untuk pengembalian rekam medis dari unit pelayanan ke ruangan assembling rekam medis (Menkes, 2008 ; Depkes R.I, 1997). Faktor-faktor pendukung ketepatan waktu pengembalian berkas rekam medis rawat inap di bagian assembling diantaranya sistem pelayanan dilaksanakan sesuai dengan Standar Operasional Prosedur (SOP), beban kerja petugas unit rawat inap, pengisian BRM, kedisiplinan dokter dalam pengisian BRM (Budi, 2011; Fauziah \& Sugiarti, 2013 ; Rachmani, 2009).

Dokumen yang lengkap adalah dokumen rekam medis yang telah diisi lengkap oleh dokter dalam waktu $<24$ jam setelah selesai pelayanan/setelah pasien rawat inap diputuskan untuk pulang yang meliputi identitas pasien, anamnesis, rencana asuhan, pelaksanaan asuhan, tindak lanjut dan resume (Kemenkes, 2002). Dokumen rekam medis diisi oleh dokter atau perawat tentang hasil kegiatan yang telah dilakukan dalam pelayanan rawat inap, namun karena kesibukan dokter dan perawat maka dokumen rekam medis tidak di isi dengan lengkap atau mungkin di catat pada formulir yang salah (Rachmani, 2009). Hasil penelitian Giyana (2012), didapatkan dari hasil observasi dokumen yang masuk ke unit rekam medis pada bagian assembling setelah di analisis secara kuantitaif dan kualitatif hampir seluruh dokumen tidak lengkap dan tidak tepat waktu dalam pengembaliaannya.

Dampak dari keterlambatan pengembalian dokumen rekam medis rawat inap ke bagian Assembling, menyebabkan keterlambatan dalam pengolahan data untuk laporan rumah sakit, dokumen rekam medis rawat inap tidak tersimpan pada rak penyimpanan dokumen sehingga menyulitkan pencarian dokumen, sedangkan bagi pasien akan mempengaruhi dalam proses pengobatan selanjutnya. Hal ini akan mempengaruhi informasi yang dilaporkan kepada pimpinan rumah sakit menjadi tidak tepat waktu dan tidak akurat sehingga menghambat kefektifan pengambilan keputusan manajemen rumah sakiserta menyebabkan keterlambatan pembuatan laporan yang dikerjakan oleh petugas 
(Fauziah \& Sugiarti, 2013). Dalam rangka peningkatan mutu pelayanan, serta mengingat pentingnya dokumen rekam medis untuk rumah sakit, maka diperlukan adanya pengendalian terhadap pengisian dokumen rekam medis (Depkes, 1997).

Berdasarkan hasil survei awal yang dilakukan di Rumah Sakit Dr. M. Yunus Bengkulu pada tanggal 8 - 22 maret 2017 masih dijumpai masalah keterlambatan pengembalian dokumen rekam medis rawat inap ke bagian assembling RSUD Dr. M. Yunus memiliki 17 ruang rawat inap, ruangan Seruni (B2) paling sering terlambat dalam pengembalian berkas rekam medis ke bagian assembling.Dari 10 berkas rekam medik yang diamati, terdapat formulir yang tidak terisi lengkap terutama pada formulir CM 2 yaitu tentang assesment awal pelayanan rawat inap sebanyak 8 berkas yang belum terisi lengkap. Sehingga dokumen tersebut belum bisa dikembalikan ke bagian assembling dalam waktu 1x24 jam (sesuai SOP).

Oleh sebab itu peneliti tertarik untuk meneliti tentang, "Analisis Keterlambatan Pengembalian Berkas Rekam Medis Rawat Inap Ruang Seruni ke Bagian Assembling di Rumah Sakit Dr. M. Yunus Bengkulu Tahun 2017'. Penelitian ini bertujuan untuk menganalisis faktor keterlambatan pengembalian berkas rekam medis (kelengkapan pengisian BRM dan pelaksanaan SOP) BRM rawat inap ke bagian assembling di RSUD Dr. Myunus Bengkulu.

\section{METODE PENELITIAN}

Jenis penelitian ini adalah observasional yaitu dengan cara pengamatan dan pengukuran terhadap variabel yang diteliti dengan rancangan penelitian deskriptif, yaitu penelitian yang bertujuan melakukan deskripsi mengenai fenomena yang ditemukan, baik yang berupa faktor resiko maupun efek atau hasil. Data hasil penelitian disajikan apa adanya, peneliti tidak menganalisis mengapa fenomena itu dapat terjadi (Sastroasmoro\& Ismael, 2010). Populasi penelitian ini adalah seluruh Dokumen Rekam Medis (DRM) pasien rawat inap Ruangan Melati pada bulan Januari-Maret 2017 yang disimpan pada bagian assembling RSUD Dr. M. Yunus Bengkulu yang berjumlah 500 DRM. Sampel penelitian ini didapat dengan menggunakan rumus besar sampel sehingga diperoleh 318 DRM yang akan diteliti. Sampel penelitian ini diambil dengan menggunakan systematic random sampling yaitu membagi jumlah atau anggota populasi dengan perkiraan jumlah sampel yang diinginkan, hasilnya adalah interval. Penelitian ini menggunakan data primer yang diukur menggunakan instrument lembar observasi dan pedoman wawancara. Setelah data terkumpul, data diolah dan dianalisis secara univariat yaitu menggambarkan masing-masing variabel menggunakan tabel distribusi frekuensi yang kemudian

\section{HASIL PENELITIAN}

Tabel 1. Distribusi Frekuensi Kelengkapan Pengisian Dokumen Rekam Medis Rawat Inap di RSUD Dr. M. Yunus Bengkulu

\begin{tabular}{|c|c|c|}
\hline Kelengkapan pengisian DRM Rawat Inap & Frekuensi & Persentase (\%) \\
\hline Tidak lengkap & 67 & 80 \\
\hline Lengkap & 16 & 20 \\
\hline Jumlah & 83 & 100 \\
\hline
\end{tabular}

Sumber :Data Primer 
Berdasarkan Tabel 1 didapatkan bawa dari 83 BRM yang diobservasi, 67 (80\%)
BRM tidak terisi lengkap pada lembar assesment awal rawat inap (CM2).

Tabel 2 Distribusi Frekuensi Pengembalian Berkas Rekam Medis Rawat Inap di RSUD Dr. M. Yunus Bengkulu

\begin{tabular}{ccc}
\hline Pengembalian Berkas Rekam Medis & Frekuensi & Persentase (\%) \\
\hline Tepat Waktu & 20 & 24 \\
\hline Tidak TepatWaktu & 63 & 76 \\
\hline Jumlah & 83 & 100 \\
\hline
\end{tabular}

Sumber : Data primer

Berdasarkan Tabel 4.2 didapatkan bahwa dari 83 BRM, 63 (76\%) BRM tidak tepat waktu dalam mengembalikan BRM

\section{PEMBAHASAN}

\section{Distribusi Frekuensi Kelengkapan Pengisian Berkas Rekam Medis Rawat Inap Ruang Seruni ke Bagian assembling}

Hasil penelitian ini didapatkan bahwa dari 83 BRM ruang rawat inap Seruni yang diobservasi, mayoritas tidak terisi lengkap oleh petugas unit rawat inap. Lembar BRM yang tidak terisi lengkap tersebut merupakan lembar asesment (CM2) rawat inap, yaitu pada lembar pemeriksaan umum yang terdiri dari kesadaran, tekanan darah, nadi, suhu, pernafasan, keadaan umum, keadaan gizi. Hasil penelitian Giyana (2012), dari 20 dokumen rekam medis setelah dianalisis kelengkapannya ada 16 dokumen tidak lengkap, ketidaklengkapan terdiri dari TTD dan Diagnosa. Dan terdapat 15 dokumen yang tidak tepat waktu pengembaliannya ke ruang Assembling.

Menurut PerMenkes (2008), syarat rekam medis yang bermutu adalah: terkait kelengkapan isian rekam medis; keakuratan; ketepatan catatan rekam medis; ketepatan waktu; dan pemenuhan persyaratan aspek hukum. Kelegkapan pengisian berkas rekam medis 24 jam setelah selesai pelayanan yang diberikan yaitu 100\%. Hasil penelitian Hastuti dari rawat inap ke ruang Assembling Unit Rekam

Medik.

(2009), dokumen yang tidak lengkap akan menghambat pelaksanaan kinerja petugas rekam medis dan dapat menjadi beban petugas dalam pengolahan data.

Hasil penelitian Winarti \& Supriyanto (2012), kelengkapan pengisian formulir rekam medis yang tidak lengkap tertinggi pada poin riwayat penyakit yaitu sebesar 38 berkas (19\%) dan diagnose sebesar 36 berkas (18\%). Hasil penelitian Pamungkas dkk (2014), menunjukkan bahwa rata-rata prosentase penilaian paling rendah adalah pada DMK 4.1 (lembar rencana pelayanan/CP) yaitu 75,4. Faktor yang menjadi penyebab utama ketidaklengkapan dokumen rekam medis pasien rawat inap adalah ketidakdisiplinan dokter dalam pengisian dokumen rekam. Hal ini dikarenakan yang menjadi prioritas utama dokter adalah pelayanan sehingga dokter terlaku sibuk dan waktunya kurang untuk mengisi dokumen rekam medis, dokter belum pernah dilakukan seminar legal aspek rekam medis.

2. Distribusi Frekuensi pengembalian berkas rekam medis rawat inap

Hasil penelitian ini didapatkan bahwa dari 83 BRM yang diobservasi, mayoritas BRM mengalami keterlambatan (tidak tepat waktu) 
pengembaliannya ke ruang Assembling Unit rekam Medis yaitu selama 5 hari. Hal ini disebabkan karena ruang Seruni mempunyai jumlah tempat tidur lebih banyak (kelas 1, kelas2 dan kelas 3) sehingga beban kerjanya pun lebih banyak.

Hasil penelitian ini berbeda dengan hasil penelitian Fauziah dan Sugiarti (2013), di Rumah Sakit Umum Daerah Tasikmalaya di unit rekam medis bagian assembling diketahui bahwa tingkat keterlambatan pengembalian dokumen rekam medis rawat inap ruang VII dengan persentase tertinggi pada bulan Desember sebanyak 84,88\%, dengan waktu pengembalian dokumen rekam medis > 14 hari setelah pasien pulang. Berdasarkan wawancara dengan Ka.Unit Rekam Medik, nilai keterlambatan pengembalian dokumen rekam medis rawat inap tinggi pada bulan Desember/akhir tahun karena kesibukan pada akhir tahun dalam pembuatan laporan tahunan rumah sakit sehingga pengolahan data terabaikan. Hasil penelitian Winarti \& Supriyanto (2012), dari 138 DRM yang tidak tepat pengembaliannya, sebanyak 95 DRM terisi lengkap dan 43 DRM tidak terisi lengkap.

Menurut Budi (2011), untuk pengembalian berkas rekam medis petugas assembling harus melakukan verifikasi pada berkas rekam medis apakah sudah lengkap atau tidak, apabila tidak lengkap maka berkas harus dikembalikan pada perawat, karena tanggung jawab dalam pengisian berkas rekam medis merupakan tanggung jawab perawat. Jika dokumen rekam medis terlambat dikembalikan maka pada pelayanan lainnya seperti pasien ingin berobat rawat jalan/kontrol ulang berkas tersebut akan terhambat pelayanan dirumah sakit akan menjadi tidak teratur dan semua pelayanan akan tidak sesuai dengan prosedur yang ditetapkan. Dan apabila dokumen rekam medis lengkap maka akan dilakukan pengkodean dan indeksing. Setelah semuanya selesai maka dokumen rekam medis rawat inap harus disusun dan dikembalikan pada rak penyimpanan (filling).

\section{Gambaran pelaksanaan SOP}

Berdasarkan wawancara langsung kepada petugas di ruang rawat inap seruni didapatkan bahwa seluruh petugas sudah mengetahui SOP mengenai pengisian dan pengambalian BRM, tetapi pada pelaksanaannya belum dikerjakan sesuai standar karena kekurangan petugas di rawat inap sejak terjadi mutasi pegawai di RSUD Dr. M. Yunus Bengkulu. Semestinya, meskipun kekurangan petugas di Ruang Seruni, petugas yang ada berusaha untuk menerapkan SOP yang telah ada agar pekerjaan terarah, efisien dan memudahkan semua unit organisasi yang ada di rumah sakit tersebut. Hasil penelitian Giyana (2012), didapatkan bahwa masing-masing petugas di setiap bagian unit rekam medis faham dengan SOP/prosedur kerja yang telah ditetapkan. Standar Operasional Prosedur (SOP) memberikan langkah benar dan terbaik berdasarkan konsekuensi bersama untuk melaksanakan berbagai kegiatan dan fungsi pelayanan yang dibuat oleh sarana pelayanan kesehatan berdasarkan standar profesi (Menkes, 2008). Berdasarkan PerMenkes (2007), Standar Prosedur Operasional adalah suatu perangkat instruksi/langkah-langkah yang dibakukan untuk menyelesaikan suatu proses kerja rutin tertentu, dimana Standar Prosedur Operasional memberikan langkah yang benar dan terbaik berdasarkan konsensus bersama untuk melaksanakan berbagai kegiatan 
dan fungsi pelayanan yang dibuat oleh sarana pelayanan kesehatan berdasarkan standar profesi. Kebijakan dan prosedur harus tersedia yang mencerminkan pengelolaan unit rekam medis dan menjadi acuan bagi staf rekam medis yang bertugas (Wijono, 2000).

\section{SIMPULAN}

Berdasarkan hasil penelitian di RSUD dr. M. Yunus Bengkulu, dapat disimpulkan sebagai berikut:

1. Dari 83 BRM yang diobservasi, 67 (80\%) BRM tidak terisi lengkap pada lembar assesment awal rawat inap (CM2), yaitu pada lembar pemeriksaan umum yang terdiri dari kesadaran, tekanan darah, nadi, suhu, pernafasan, keadaan umum, keadaan gizi.

2. Dari 83 BRM, 63 (76\%) BRM tidak tepat waktu dalam mengembalikan BRM dari rawat inap ke ruang Assembling Unit Rekam Medik yaitu selama 5 hari.

3. Berdasarkan wawancara langsung kepada petugas di ruang rawat inap seruni didapatkan bahwa seluruh petugas sudah mengetahui SOP mengenai pengisian dan pengambalian BRM, tetapi pada pelaksanaannya belum dikerjakan sesuai standar.

\section{SARAN}

Berdasarkan hasil penelitian, maka dapat disusun saran-saran sebagai berikut:

1. Penanggung jawab ruang rawat inap (Ka.ruang) terus mengingatkan perawat dan dokter yang bertugas sejak pasien dirawat sampai 1 hari setelah pasien pulang untuk melengkapi semua catatan medic pasien per lembar dokumen. Ka.Unit rekam medic melakukan kontrol kepada Ka.ruang rawat inap agar semua sistem dapat berjalan lancar
2. Meningkatkan kedisiplinan perawat dan petugas agar pengembalian berkas ke unit rekam medic pada bagian Assembling tepat waktu sesuai standar dengan cara memberikan pengetahuan kepada petugas pentingnya mengetahui dampak tidak tertibnya administrasi dalam menjaga mutu Rumah Sakit.

3. Perlunya sosialisasi tentang SOP kepada petugas rawat inap dan meningkatkan fungsi manajemen Ka.Tim dan $\mathrm{Ka}$. ruangan.

\section{DAFTAR PUSTAKA}

Budi, S. C. 2011. Manajemen Unit Kerja Rekam Medis. Yogyakarta : Quantum Sinergis Media.

Departemen Kesehatan Republik Indonesia, 1997. Pedoman Rekam Medis Rumah Sakit. Jakarta: Dirjen Bina Pelayanan Medik.

Departemen Kesehatan Republik Indonesia. 2006. Pedoman Penyelenggaraan dan Prosedur Rekam Medis Rumah Sakit di Indonesia Revisi II. Jakarta : Depkes RI

Departemen Kesehatan Republik Indonesia, 2008. Standart Pelayanan Minimal Rumah Sakit, Dirjen Bina Pelayanan Medik, Jakarta.

Djojodibroto, D. 1997. Kiat Mengelola Rumah Sakit. Jakarta: Hipokrates

Fauziah, U dan Sugiarti, I. 2013. Gambaran Pengembalian Dokumen Rekam Medis Rawat Inap Ruang VII Triwulan IV Tahun 2013 Di Rumah Sakit Umum Daerah Tasikmalaya. Jurnal Manajemen Informasi Kesehatan Indonesia, ISSN:2337-585X, Vol.2, No.1, Maret 2014.

Gafur, K, M, A. Pentingnya Peningkatan Profesionalisme Rekam Medis dalam Upaya Peningkatan Mutu Pelayanan Kesehatan. Kumpulan Makalah Seminar Nasional dalam Kongres dan Rakernas I-III PORMIKI. Jakarta; 2003

Giyana, F. Analisis Sistem Pengelolaan Rekam Medis Rawat Inap Rumah Sakit Umum Daerah Kota Semarang. Jurnal Kesehatan Masyarakat, Volume 1, Nomor 2, Tahun 2012, Halaman $48-61$

Hastuti SD, Sugiarsi S, dan Lestari T. Analisis Keterlambatan Pengembalian Dokumen Rekam Medis Pasien Rawat Inap di Bagian Asembling di RSU PKU Muhammadiyah 
Delangu Triwulan I tahun 2009. Jurnal Rekam Medis. 2009; 3(1): 43-59.

Keputusan Menteri Kesehatan Republik Indonesia. KEMENKES No: 228/MENKES/Sk/III/2002 tentang Pedoman Penyusunan Standar Pelayanan Minimal Rumah Sakit yang Wajib Dilaksanakan Daerah.

Menkes. 2007. Keputusan Menteri Kesehatan Republik Tentang Standar Profesi Perekam Medis dan Informasi Kesehatan. Jakarta.

Menteri Kesehatan RI. 2008. Peraturan Menteri Kesehatan Republik Indoneseia Nomor 269/Menkes/PER/III/2008 Tentang Rekam

Menteri Kesehatan Republik Indonesia. 2013. Peraturan Menteri Kesehatan Nomor 55 Tahun 2013 tentang Penyelenggaraan Pekerjaan Perekam Medis, Jakarta: Departement Kesehatan Republik Indenesia.
Pamungkas, F., Hariyanto, T., Woro, E. Identifikasi Ketidaklengkapan Dokumen Rekam Medis Rawat Inap di RSUD Ngudi Waluyo Wlingi. Jurnal Kedokteran Brawijaya, Vol. 28, Suplemen No. 2, 2015

Rachmani, E. 2009. Analisa Keterlambatan Penyerahan Dokumen Rekam Medis Rawat Inap Di Rumah Sakit Polri Dan Tni Semarang. JURNAL VISIKES - Vol. 9 / No. 2 / September 2010

Wijono D, 2000. Manajemen Mutu Pelayanan Kesehatan Vol.2, Airlangga University Press, Surabaya.

Winarti dan Supriyanto, S. 2012. Analisis Kelengkapan Pengisian Dan Pengembalian Rekam Medis Rawat Inap Rumah Sakit. Jurnal Administrasi Kesehatan Indonesia Volume 1 Nomor 4 September-Desember 2013 